\title{
Twin-to-Twin Transfusion Syndrome
}

\author{
Sharma $D^{1}$, Garg $E^{2}$ \\ ${ }^{1}$ Dr. Deepak Sharma, ${ }^{2}$ Dr. Eva Garg. Both are from \\ the Department of Paediatrics, Pt.B.D.S PGIMS \\ Rohtak,Haryana, India. Pin 124001
}

\section{The Case}

Primigravida, delivered Monochorionic Diamniotic (MCDA) twins at $28+6$ weeks in view of Premature Prolonged Rupture of Membranes (PPROM). Both babies were females with weight of 1220 and 720 grams respectively. Babies cried immediately and were admitted in nursery in view of respiratory distress and prematurity. Both babies received surfactant and respiratory support. Babies had weight discordance of $40.98 \%$. Baby 1 was plethoric with $\mathrm{Hb}$ of $22.2 \mathrm{gm} / \mathrm{dl}$ and PCV of $63.8 \%$. Baby 2 was pale with $\mathrm{Hb}$ of $6.4 \mathrm{gm} /$ $\mathrm{dl}$ and PCV of $19.1 \%$. Repeat PCV done of baby 1 at 14 hours of age showed $\mathrm{Hb}$ of $24.2 \mathrm{gm} / \mathrm{dl}$ and $\mathrm{PCV}$ of $67.9 \%$. Baby 1 had recurrent apneas at age of 23 hours for which partial exchange transfusion was done with normal saline. PCV after the exchange dropped to 50.6 $\%$. Baby 2 received one unit of packed RBC in view of anaemia. Rest of the nursery stay was uneventful and were discharged.

\section{Discussion}

TTTS is a specific condition that only occurs in multiple pregnancies of monozygotic (monochorionic) twins. When twins share a single placenta, the blood vessels become mutually interconnected in the placenta, so that blood flows back and forth between both twins ${ }^{1}$. The diagnosis of TTTS was made based on neonatal criteria of greater than $20 \%$ discordance in birth weight, and greater than $5 \mathrm{~g} / \mathrm{dL}$ discordance in cord haemoglobin levels ${ }^{2}$. They have been replaced with more stringent ultrasound based criteria, with particular attention to amniotic fluid discordance, bladder volumes, and fetal echocardiography and Doppler studies.

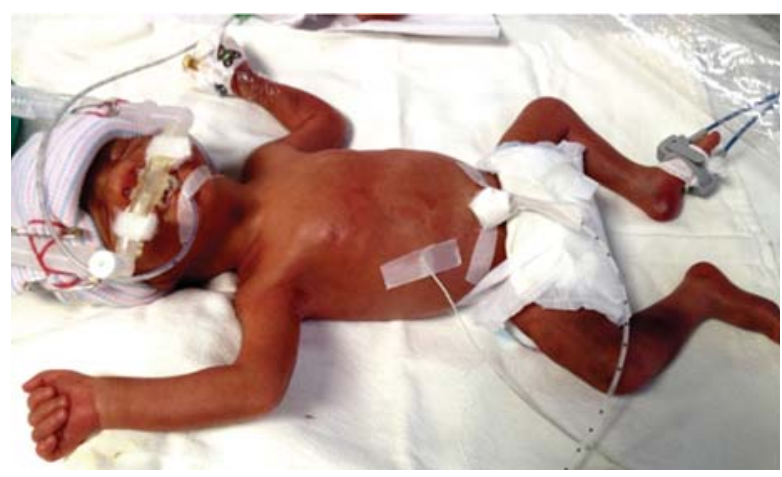

Fig 1: Showing first baby having polycythaemia and required exchange transfusion

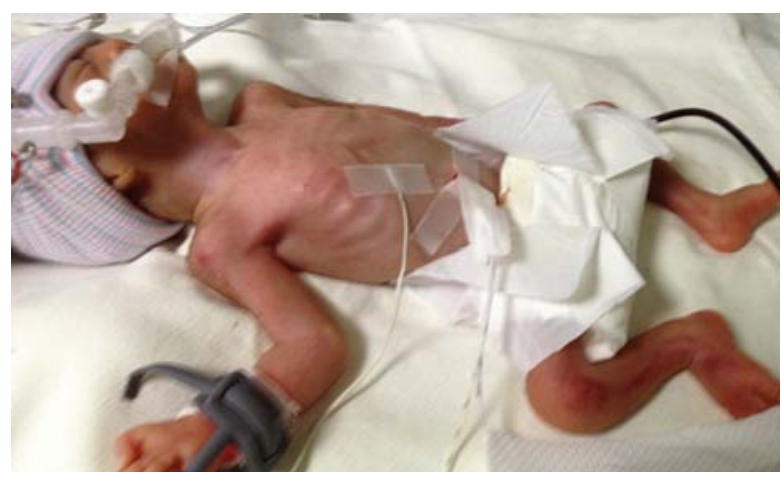

Fig 2: Showing second baby having anaemia and required blood transfusion

\section{References}

1. Urig MA, Clewell WH, Elliot JP. Twin-twin transfusion syndrome. Am J Obstet Gynecol 1990;163:1522-6.

2. Quintero RA. Twin-twin transfusion syndrome. Clin Perinatol 2003;30:591-600.

\section{Address for correspondence \\ Dr. Eva Garg \\ E-mail: doc.eva14@gmail.com}

This work is licensed under a Creative Commons Attribution 3.0 License.

\section{How to cite this article?}

Sharma D, Garg E. Twin-to-Twin Transfusion Syndrome. J Nepal Paediatr Soc 2013;33(2):157. 